\title{
PELATIHAN MENGATASI KECEMASAN BERBICARA DI DEPAN UMUM PADA KADER KESEHATAN JIWA
}

\author{
Ika Pratiwi Wibawanti' ${ }^{1)}$, Endah Puspita Sari' ${ }^{2)}$, Vequentina Puspa ${ }^{3)}$ \\ 1)Puskesmas Umbulharjo 2, Kota Yogyakarta, Daerah Istimewa Yogyakarta \\ 2)Program Studi Psikologi, Universitas Islam Indonesia, Yogyakarta \\ Kampus Terpadu Universitas Islam Indonesia, Jl. Kaliurang km. 14,5 \\ Besi, Sleman, Yogyakarta, 5584 \\ Surel: endah_puspita_sari@uii.ac.id \\ 3)Puskesmas Cangkringan, Sleman, Daerah Istimewa Yogyakarta
}

\begin{abstract}
ABSTRAK
Kader merupakan anggota masyarakat yang mewakili wilayahnya untuk menjadi penghubung antara Puskesmas dan masyarakat dan membantu Puskesmas dalam suatu cakupan kerja tertentu. Selain kader posyandu yang sudah lama dikenal, saat ini di beberapa wilayah di kabupaten Sleman juga memiliki kader kesehatan jiwa. Permasalahan yang terjadi pada kader kesehatan jiwa di Puskesmas Cangkringan adalah kecemasan saat berbicara di depan masyarakat untuk menyampaikan pesan dari Puskesmas. Pelatihan ini dilakukan untuk menurunkan kecemasan berbicara di depan umum pada kader kesehatan jiwa Puskesmas Cangkringan. Untuk mencapai tujuan tersebut, peneliti menggunkan quasi experimental onegroup pre-test and post-test dengan within group analysis. Pengukuran pre-test dan post-test kelompok dilakukan menggunakan modifikasi alat ukur Back Anxiety Inventory. Hasil pengukuran menggunakan paired sample T-test menunjukan $t=5.647$ dengan $p=0.000(p<$ 0.01 ). Artinya pelatihan mengatasi kecemasan berbicara di depan umum yang dilakukan pada kader kesehatan jiwa Puskesmas Cangkringan mampu menurunkan kecemasan dengan sangat signifikan.
\end{abstract}

Kata Kunci: pelatihan, kecemasan berbicara di depan umum, kader kesehatan jiwa, puskesmas

\begin{abstract}
Cadre is a member of the community representing its territory to serve as a mediator between Puskesmas (Community Health Center) and the community and assist the Puskesmas within a certain scope of work. In addition to posyandu cadres that have long been known, currently in some areas in Sleman district also has mental health cadres. One problem that occured in the mental health cadres at Cangkringan Community Health Center was communication apprehension among the mental health cadres to deliver a message from Puskesmas. This training was conducted to reduce communication apprehension on mental health cadres of Puskesmas Cangkringan. To achieve these objectives, we used quasi experimental one-group pre-test and post-test with within group analysis. The pre-test and post-test group measurements were performed using a modified Back Anxiety Inventory measurement tool. The measurement result using paired sample T-test shows $t=5.647$ with $p=0.000(p<$ 0.01). This means that the training was able to reduce communication apprehension to mental health cadre with a very significant.
\end{abstract}

Key words: training, communication apprehension, mental health cadre,Puskesmas 


\section{PENDAHULUAN}

Wilayah Cangkringan merupakan wilayah yang terkena dampak paling luas akibat erupsi merapi tahun 2010. Sebagian besar wilayah Cangkringan rusak terkena awan panas dan lahar dingin. Jumlah korban jiwa terbanyak akibat erupsi merapi berasal dari wilayah Cangkringan. Akibat bencana alam tersebut, banyak warga yang kehilangan keluarga dan sanak saudara, tempat tinggal, hewan ternak, pekerjaan dan lahan pertanian untuk mencari nafkah. Perubahan yang terjadi akibat bencana alam tersebut, adalah banyak warga yang kemudian berisiko mengalami gangguan jiwa; mulai dari gangguan jiwa yang ringan sampai dengan gangguan jiwa yang berat. Berdasarkan pendataan yang dilakukan pada tahun 2011, terdapat 43 warga yang mengalami gangguan jiwa berat.

Melihat banyaknya warga yang memiliki faktor risiko dan keterbatasan tenaga kesehatan di Puskesmas Cangkringan, serta adanya program pemerintah untuk membentuk Desa Siaga Sehat Jiwa, maka dibentuklah kader-kader kesehatan jiwa perwakilan dari setiap dusun. Fungsi kader adalah sebagai perpanjangan tangan dari Puskesmas yang bertugas untuk memberikan penyuluhan kepada warga mengenai kesehatan jiwa serta melakukan screening kesehatan jiwa terhadap warganya. Apabila kader menemukan ada warga yang memiliki gejala gangguan kesehatan jiwa, kader diminta segera melaporkan kepada petugas Puskesmas untuk segera ditindaklanjuti. Sebagai bentuk sosialisasi terhadap warga, kader harus melakukan penyuluhan terhadap sekitar 45 warga di dusunnya mengenai kesehatan jiwa, agar warga paham mengenai masalah kesehatan jiwa. Sejauh ini warga masih memiliki persepsi bahwa yang dimaksud dengan gangguan jiwa pasti selalu "orang gila" atau individu skizofrenia.

Dalam pertemuan antara petugas Puskesmas dan kader kesehatan jiwa, para kader diberi pengetahuan singkat tentang kesehatan jiwa. Saat kader diberi kesempatan bertanya, sebagian besar kader memilih untuk bertanya secara personal setelah acara selesai. Pun saat kader melakukan sosialisasi pertama kali ke dusun masing-masing, petugas Puskesmas masih mendampingi para kader, sebagian kader masih menolak untuk berbicara di depan warga dan menyatakan malu kalau harus berbicara di depan warga. Ketika peneliti mencoba menggali lebih jauh, para kader menjawab bahwa merasa belum pantas untuk melakukan penyuluhan ke warga, takut salah, malu, tidak percaya diri, dan takut ditertawakan jika sampai salah mengucapkan kata-kata.

Ketika peneliti mendampingi salah satu kader saat memberikan penyuluhan ke warga di dusunnya, praktikan melihat kader tersebut mengalami kecemasan. Hal ini tampak dari suara kader yang gemetar, tangan yang gemetar dan dingin, materi yang disampaikan tidak runtut, sehingga warga kurang memahami alur pembicaraan yang disampaikan kader. Di dusun lain, kader yang sudah dibekali materi kesehatan jiwa sama sekali tidak mau berbicara di depan warga karena merasa tidak percaya diri, sehingga kader tersebut menyerahkan sepenuhnya kepada petugas dari Puskesmas untuk memberikan penyuluhan kepada warganya. Setelah selesai penyuluhan, kader tersebut tampak lega dan menyatakan kepada peneliti dan petugas Puskesmas bahwa dirinya berharap mendapatkan tips-tips agar tidak gugup saat berbicara di depan warga.

Selanjutnya peneliti melakukan wawancara dengan beberapa kader di beberapa dusun yang berbeda. Para kader tersebut menyatakan bahwa belum percaya diri dan belum berani jika diminta untuk memberikan penyuluhan kepada warga walaupun sudah dibekali materi dari Puskesmas. Ada kader yang bercerita bahwa saat sebelum tampil tangan gemetar, jantung berdebar-debar, keringat dingin, dan gugup. Beberapa kader bahkan merasakan perut terasa mulas ketika hendak berbicara di depan warga. Salah satu kader mengaku bahwa kalimat menjadi tidak beraturan dan urutan materi menjadi kacau karena mendadak lupa hal apa yang akan disampaikan. Para kader yang diwawancarai berharap ada pelatihan berbicara di depan 
umum karena membutuhkan materi dan tips agar program-program Puskesmas tentang kesehatan jiwa yang sudah dipercayakan kepada para kader dapat dilaksanakan dengan baik.

Kemudian peneliti melakukan wawancara kepada psikolog Puskesmas Cangkringan. Psikolog Puskesmas menyatakan bahwa sebetulnya permasalahan kecemasan berbicara di depan warga tidak hanya terjadi pada kader kesehatan jiwa, tapi juga pada kader lansia dan kader balita. Sebagian besar kader kesehatan jiwa ketika didampingi petugas untuk menyampaikan materi kepada warga, memilih untuk membacakan materi daripada berbicara secara interaktif dengan warga. Situasi seperti ini tentu saja membuat warga yang mendengarkan menjadi kurang tertarik terhadap materi kesehatan jiwa, karena semua warga juga diberikan buku yang dibacakan oleh para kader.

Terakhir, peneliti menyebarkan 50 kuesioner kecemasan berbicara di depan umum kepada para kader; baik kader balita, lansia, dan kesehatan jiwa. Hasil kuesioner menunjukkan bahwa dari 50 kader, 45 kader memiliki kecemasan berbicara di depan warga, sedangkan 5 kuesioner tidak dikembalikan. Artinya semua kader memiliki kecemasan berbicara di depan warga. Untuk tahap pertama, peneliti berfokus pada kader kesehatan jiwa karena kader kesehatan jiwa yang harus banyak tampil sosialisasi di depan forum warga, juga kader kesehatan jiwa terbentuk terakhir dibanding kader balita dan kader lansia.

Berdasarkan uraian di atas, diketahui bahwa adanya risiko mengalami gangguan jiwa karena kondisi lingkungan alam dan keterbatasan pengetahuan warga mengenai kesehatan jiwa, maka diperlukan kader-kader yang mampu menyampaikan pengetahuan mengenai kesehatan jiwa dan melakukan screening kepada warga masyarakatnya. Namun, di kalangan kader itu sendiri terdapat beberapa permasalahan yang dapat menghambat proses penyampaian pengetahuan kepada warga. Permasalahan yang dihadapi para kader antara lain:

1. Pengetahuan kader terhadap kesehatan jiwa masih belum memadai, sehingga masih diperlukan pembekalan mengenai kesehatan jiwa bagi para kader kesehatan jiwa

2. Sebagian besar kader masih merasa tidak percaya diri dan cemas ketika harus diminta untuk memberikan penyuluhan kepada warganya.

\section{TINJAUAN PUSTAKA}

Kecemasan berbicara di depan umum didefinisikan sebagai ketakutan atau kecemasan yang terkait dengan hal-hal nyata atau hal-hal yang belum terjadi dalam hal berkomunikasi dengan individu lain (McCroskey \& Richmond, 1976). McCroskey, Richmond, Dali, \& Falcione (1977) menyatakan bahwa individu yang memiliki kecemasan berbicara di depan umum memiliki kecenderungan yang lebih besar untuk khawatir, tidak efektif dalam berinteraksi dengan audiens, dan bahkan ada yang menarik diri dari individu lain. McCroskey \& Richmond (1976) menjelaskan bahwa yang dimaksud dengan menarik diri dari individu lain pada individu yang memiliki kecemasan berbicara di depan umum artinya adalah menghindari sama sekali untuk tampil di hadapan audiens atau mengurangi partisipasi untuk tampil di hadapan audiens jika kebutuhan untuk tampil tidak dapat dihindari. Adapun malu (shyness) adalah predisposisi untuk menarik diri atau menghindari komunikasi dengan individu lain. Jika kecemasan berbicara di muka umum lebih bersifat subjektif karena merupakan pengalaman afektif, kalau malu kecenderungan berperilaku yang disebabkan oleh kecemasan berbicara di muka umum atau karena sebab yang lainnya (McCroskey \& Beatty, 1986). McCroskey (1984) menegaskan bahwa kecemasan berbicara di depan umum disebabkan oleh kognisi, bukan oleh perilaku.

Berdasarkan permasalahan yang terjadi, kader akan diberikan pelatihan untuk mengelola kecemasan ketika akan berbicara di depan umum. Pelatihan berupa psikoedukasi megenai terjadinya kecemasan, persiapan yang diperlukan sebelum berbicara di depan umum, dan 
manfaat teknik relaksasi juga terapi kognitif yang sederhana. Melalui pelatihan ini kader diharapkan dapat menerapkan teknik-teknik yang diajarkan untuk menurunkan ketegangan yang dirasakan oleh para kader sehingga jika kader berada dalam keadaan yang rileks harapannya kader dapat berpikir dengan tenang dan konsentrasi, akibatnya kader mampu untuk berbicara dengan lancar dan efektif.

\section{BAHAN DAN METODE}

Pelatihan dilakukan oleh peneliti bersama psikolog Puskesmas Cangkringan. Program pelatihan yang dilakukan memiliki tujuan sebagai berikut:

1. Untuk memberikan informasi kepada kader-kader kesehatan jiwa mengenai kecemasan, terjadinya kecemasan, peran pola pikir dalam terjadinya kecemasan, dampak yang ditimbulkan oleh kecemasan dan cara meredakan kecemasan, dalam kaitannya ketika hendak berbicara di muka umum

2. Agar kader memahami bagaimana terjadinya kecemasan, memahami peran pola pikir dalam meredakan kecemasan, serta memahami teknik-teknik yang dapat digunakan untuk megatasi kecemasan saat berbicara di depan warga

3. Untuk membekali kader mengenai hal-hal apa saja yang perlu dilakukan sebelum melakukan penyuluhan kepada warga

4. Kader dapat berlatih secara langsung dan menerapkan tips dan teknik yang diberikan melalui latihan berbicara di depan anggota kelompok

Umumnya para ahli membedakan antara pendidikan dan pelatihan. Pendidikan adalah perolehan informasi atau pengetahuan. Pelatihan adalah perolehan keterampilan; baik kognitif atau psikomotorik (Gallagher, Ritter, Champion, Higgins, Fried, Moses, Smith, \& Satava, 2005). Berdasarkan pendapat tersebut maka program intervensi yang diberikan kepada para kader adalah program pelatihan. Para peserta pelatihan akan mempelajari pengetahuan dan keterampilan yang sifatnya praktis untuk tujuan tertentu.

Pelatihan ini ditujukan kepada kader-kader kesehatan jiwa yang memiliki tingkat kecemasan berbicara di depan umum dan bersedia mengikuti pelatihan. Jumlah kader yang diundang adalah 20 kader, yang berasal dari berbagai dusun. Penelitian ini menggunakan desain quasi experimental one-gorup pre-test dan post-test dengan within group analysis.

Alat dan bahan yang diperlukan dalam pelatihan ini adalah alat tulis, white board, LCD, speaker, kamera, lembar materi, dan lembar pretest-posttest. Aspek-aspek yang terdapat dalam lembar pretest-posttest diambil dari aspek-aspek kecemasan dari Beck (BAI/Beck Anxiety Inventory). Masing-masing aspek dibuat dalam 4 tingkatan, yaitu tidak cemas sama sekali (0), ringan (1), sedang (2), dan berat (3). Tingkatan tersebut menunjukkan tingkat keparahan masing-masing aspek. Peserta diminta untuk mengukur tingkat keparahan dari masing-masing aspek, mulai dari 0 (tidak merasakan kecemasan sama sekali) sampai dengan 3 (merasakan aspek gejala cemas yang berat).

Materi pelatihan adalah tentang definisi kecemasan, sebab-sebab terjadinya kecemasan, peran pola pikir terhadap timbulnya kecemasan, dan cara mengatasi kecemasan saat berbicara di depan umum, juga pengetahuan tentang relaksasi dan afirmasi positif. Selain itu, peserta juga diberi tips-tips sederhana dan aplikatif tentang persiapan apa saja yang diperlukan sebelum menyampaikan materi kepada warga. Setelah mengikuti materi secara lengkap, peserta pelatihan akan dibagi menjadi tiga kelompok. Masing-masing kelompok terdiri dari $5-6$ anggota kelompok. Masing-masing peserta diminta untuk berlatih berbicara di depan anggota kelompoknya sambil menerapkan tips-tips yang sudah diberikan.

Adapun rancangan intervensi yang akan dilakukan adalah sebagai berikut: 
Tabel 1. Rancangan pelatihan mengatasi kecemasan berbicara di depan umum bagi kader kesehatan jiwa

\begin{tabular}{|c|c|c|c|}
\hline Sesi & Kegiatan & Waktu & Tujuan \\
\hline 1 & $\begin{array}{l}\text { - Pembukaan dan perkenalan } \\
\text { - Membuat kesepakatan mengenai } \\
\text { kontrak kegiatan } \\
\text { - Formulasi masalah }\end{array}$ & $\begin{array}{l}30 \\
\text { menit }\end{array}$ & $\begin{array}{l}\text { - Untuk membangun rapport } \\
\text { dan menjalin keakraban } \\
\text { dengan para peserta } \\
\text { - Untuk membuat kegiatan } \\
\text { menjadi terarah dan mencapai } \\
\text { tujuan } \\
\text { - Untuk memberikan } \\
\text { kesimpulan atas hasil asesmen } \\
\text { yang sudah dilakukan } \\
\end{array}$ \\
\hline 2 & $\begin{array}{l}\text { - } \text { Pretest } \\
\text { - Psikoedukasi tentang kecemasan, } \\
\text { relaksasi, afirmasi positif, serta } \\
\text { persiapan yang diperlukan } \\
\text { sebelum berbicara di depan } \\
\text { umum }\end{array}$ & 1 jam & $\begin{array}{l}\text { - Untuk melihat tingkat } \\
\text { kecemasan sebelum pelatihan } \\
\text { dilakukan } \\
\text { - Untuk memberikan } \\
\text { pengetahuan tentang apa itu } \\
\text { kecemasan, bagaimana } \\
\text { terbentuknya kecemasan, } \\
\text { sensasi yang dirasakan saat } \\
\text { merasakan kecemasan, dan } \\
\text { dampak dari kecemasan } \\
\text { - Untuk memberikan } \\
\text { pengetahuan tentang peran } \\
\text { perubahan pola pikir, teknik } \\
\text { relaksasi, dan afirmasi positif } \\
\text { dalam mengatasi kecemasan }\end{array}$ \\
\hline 3 & $\begin{array}{l}\text { Latihan mengidentifikasi pikiran- } \\
\text { pikiran yang membuat cemas, } \\
\text { (testing realitas), afirmasi positif, } \\
\text { dan latihan relaksasi }\end{array}$ & $\begin{array}{l}30 \\
\text { menit }\end{array}$ & $\begin{array}{l}\text { - Untuk melatih keterampilan } \\
\text { peserta dalam mengidentifikasi } \\
\text { hal-hal yang membuat cemas, } \\
\text { lalu melakukan testing realitas. } \\
\text { - Untuk meningkatkan pikiran } \\
\text { positif dan mengelola sensasi } \\
\text { fisik dengan deep breathing }\end{array}$ \\
\hline 4 & $\begin{array}{l}\text { - Praktik berbicara di depan teman } \\
\text { satu kelompok (peserta } \\
\text { bekelompok } 3 \text { orang, semua } \\
\text { mendapat kesempatan yang sama } \\
\text { untuk bergantian berbicara di } \\
\text { depan teman satu kelompok) } \\
\text { - Evaluasi praktek berbicara di } \\
\text { depan teman satu kelompok }\end{array}$ & 1 jam & $\begin{array}{l}\text { - Untuk melatih peserta } \\
\text { berbicara secara langsung di } \\
\text { depan forum kecil } \\
\text { - Untuk mendapatkan umpan } \\
\text { balik atas kelebihan dan } \\
\text { kelemahan yang masih } \\
\text { dilakukan, kemudian } \\
\text { mendiskusikan apa yang bisa } \\
\text { dilakukan untuk perbaikan ke } \\
\text { depan }\end{array}$ \\
\hline 5 & $\begin{array}{l}\text { - Evaluasi kegiatan secara } \\
\text { keseluruhan } \\
\text { - Posttest }\end{array}$ & $\begin{array}{l}30 \\
\text { menit }\end{array}$ & $\begin{array}{l}\text { - Untuk mengetahui perubahan- } \\
\text { perubahan yang dirasakan oleh } \\
\text { para peserta }\end{array}$ \\
\hline
\end{tabular}




\begin{tabular}{|l|l|l|l|}
\hline & & & $\begin{array}{l}\text { - Untuk melihat tingkat } \\
\text { kecemasan peserta setelah } \\
\text { dilakukan pelatihan }\end{array}$ \\
\hline 6 & Terminasi & $\begin{array}{l}15 \\
\text { menit }\end{array}$ & $\begin{array}{l}\text { - Untuk mengakhiri pelatihan } \\
\text { - Untuk menyemangati peserta } \\
\text { untuk mau berlatih di rumah } \\
\text { dan berani berlatih tampil di } \\
\text { forum-forum dusun }\end{array}$ \\
\hline 7 & Follow up & $\begin{array}{l}\text { Untuk memantau perubahan yang } \\
\text { terjadi }\end{array}$ \\
\hline
\end{tabular}

\section{HASIL DAN PEMBAHASAN}

Pelaksanaan pelatihan dilakukan di aula Puskesmas Cangkringan pada hari sabtu, 3 Maret 2012 jam 09.00 - 12.00 WIB. Sebelumnya peneliti menyebar 20 undangan kepada 20 kader kesehatan jiwa (satu dusun diberikan 2 undangan untuk 2 kader), namun hanya 17 kader yang hadir. Ketujuhbelas kader berasal dari berbagai dusun, dan bersedia menjadi peserta dengan mengisi informed consent. Semua peserta berjenis kelamin perempuan. Latar belakang pendidikan para peserta antara lulusan SMP sampai lulusan diploma 3. Latar belakang pekerjaan para peserta adalah petani dan ibu rumah tangga. Semua dusun memiliki wakil yang hadir sebagai peserta pelatihan.

Berdasakan hasil pretest dan posttest, terdapat penurunan tingkat kecemasan pada masingmasing peserta. Data pretest dan posttest masing-masing peserta adalah sebagai berikut:

Tabel 2. Hasil Pretest dan Posttest

\begin{tabular}{|c|c|c|c|}
\hline NAMA & PRETEST & POSTTEST & Keterangan \\
\hline Peserta 1 (SP) & 29 & 23 & Turun \\
\hline Peserta 2 (ED) & 25 & 16 & Turun \\
\hline Peserta 3 (KS) & 32 & 19 & Turun \\
\hline Peserta 4 (SM) & 27 & 27 & Turun \\
\hline Peserta 5 (PR) & 28 & 23 & Turun \\
\hline Peserta 6 (JM) & 25 & 20 & Turun \\
\hline Peserta 7 (DH) & 39 & 21 & Turun \\
\hline Peserta 8 (ST) & 45 & 43 & Turun \\
\hline Peserta 9(A) & 30 & 25 & Turun \\
\hline Peserta 10 (SY) & 36 & 24 & Turun \\
\hline Peserta 11 (MR) & 32 & 32 & Turun \\
\hline Peserta 12 (SW) & 22 & 21 & Turun \\
\hline Peserta 13(MJ) & 10 & 21 & Turun \\
\hline Peserta 14 (SN) & 32 & 24 & Turun \\
\hline Peserta 15 (SK) & 35 & 30 & Turun \\
\hline Peserta 16(YA) & 38 & 24 & Turun \\
\hline Peserta 17 (SH) & 27 & & Turun \\
\hline
\end{tabular}

Untuk mengevaluasi hasil penerapan program pelatihan mengelola kecemasan berbicara di depan umum pada kader kesehatan jiwa Puskesmas Cangkringan, maka peneliti melakukan perhitungan mean total skor kecemasan yang dimiliki peserta saat pretest dan posttest. Tabel 3 menunjukkan hasil perhitungan mean total skor dari kedua pengukuran tersebut. 
Tabel 2. Hasil perbedaan mean skor total pretest dan posttest

Paired Samples Statistics

\begin{tabular}{|rl|r|r|r|r|}
\hline & Mean & N & Std. Deviation & Std. Error Mean \\
\hline \multirow{2}{*}{ Pair 1 } & pretest & 30.1176 & 17 & 7.82530 & 1.89791 \\
& posttest & 23.1765 & 17 & 8.37582 & 2.03144 \\
\hline
\end{tabular}

Dari tabel tersebut terlihat bahwa terjadi penurunan mean skor peserta sebelum dan setelah pelatihan dilaksanakan. Selain itu, peneliti juga melihat efektivitas hasil penerapan program pelatihan mengelola kecemasan berbicara di depan umum maka dilakukan analisis paired sample T-test. Berdasarkan analisis menggunakan uji T-Test didapatkan hasil pada tabel 4 sebagai berikut :

Tabel 4. Hasil Perhitungan Statistik

Paired Samples Test

\begin{tabular}{|c|c|c|c|c|c|c|c|c|c|}
\hline & & \multicolumn{5}{|c|}{ Paired Differences } & \multirow[b]{3}{*}{$\mathrm{T}$} & \multirow[b]{3}{*}{ Df } & \multirow{3}{*}{$\begin{array}{l}\text { Sig. (2- } \\
\text { tailed) }\end{array}$} \\
\hline & & \multirow[b]{2}{*}{ Mean } & \multirow{2}{*}{$\begin{array}{c}\text { Std. } \\
\text { Deviation } \\
\end{array}$} & \multirow{2}{*}{$\begin{array}{l}\text { Std. } \\
\text { Error } \\
\text { Mean }\end{array}$} & \multicolumn{2}{|c|}{$\begin{array}{c}95 \% \text { Confidence } \\
\text { Interval of the } \\
\text { Difference }\end{array}$} & & & \\
\hline & & & & & Lower & Upper & & & \\
\hline Pair 1 & $\begin{array}{l}\text { pretest - } \\
\text { posttest }\end{array}$ & 6.94118 & 5.06792 & 1.22915 & 4.33549 & 9.54686 & 5.647 & 16 & .000 \\
\hline
\end{tabular}

Tabel 4 menunjukkan bahwa terdapat perbedaan yang sangat signifikan antara hasil perhitungan total skor pretest dan posttest $(\mathrm{t}=5.647$ dengan nilai Sig. $0.000(\mathrm{P}<0.01))$. Artinya program pelatihan mengelola kecemasan berbicara di depan umum pada kader kesehatan jiwa di Puskesmas Cangkringan berpengaruh dalam menurunkan kecemasan yang dimiliki peserta.

Kelly (Dwyer, 200) menyatakan bahwa intervensi yang diberikan kepada individu yang mengalami kecemasan berbicara di muka umum harus dilihat dari faktor penyebabnya. Lebih jauh Dwyer (200) menyatakan bahwa jika penyebab dari kecemasan berbicara di depan umum adalah keterbatasan pengetahuan tentang komunikasi efektif maka yang perlu diberikan adalah pelatihan berbicara di depan umum yang efektif. Jika yang menjadi penyebab adalah kecemasan maka terapi relaksasi menjadi jawaban atas penyebab tersebut. Namun, jika yang menjadi penyebab adalah pemikiran-pemikiran negatif tentang berbicara di depan umum maka intervensi yang diberikan adalah terapi kognitif.

Utami \& Prawitasari (1991) dalam penelitiannya mendapatkan hasil bahwa pada umumnya kecemasan berbicara di muka umum bukan disebabkan oleh ketidakmampuan individu, tapi 
sering disebabkan oleh pikiran-pikiran negatif yang tidak rasional. Hal ini terjadi pada kader kesehatan jiwa Puskesmas Cangkringan. Kader menetapkan tujuan bagi dirinya sendiri agar mampu berbicara di depan warga dengan baik, mampu menyampaikan materi dan dapat memberikan jawaban terhadap pertanyaan para warga dengan meyakinkan. Namun, kader merasa bahwa belum memiliki kesiapan yang cukup, dan takut ditertawakan jika melakukan kesalahan. Proses kognitif ini kemudian memunculkan rasa cemas ketika hendak berbicara di depan warga. Oleh karena itu dalam salah satu sesi yang diberikan kepada peserta adalah salah satu teknik di dalam terapi kognitif, yaitu testing realitas (Neenan \& Dryden, 2011). Testing realitas adalah proses evaluasi yang dilakukan oleh individu apakah pemikiran yang dimilikinya menguatkan atau berlawanan dengan hipotesa pemikirannya, lalu individu diyakinkan bahwa hipotesa pemikirannya adalah asumsi, sehingga sehingga individu harus membangun keterampilan agar hipotesa pemikirannya valid (Nelson-Jones dalam Neenan \& Dryden, 2011).

Kecemasan berbicara di muka umum akan menggejala dalam bentuk reaksi-reaksi fisiologis dan psikologis. Reaksi fisiologis ditunjukkan dengan adanya peningkatan denyut jantung, muka merah, suara bergetar, mulut kering, bagian-bagian tubuh berkeringat, dan otot-otot menjadi tegang. Reaksi psikologis berupa merasa bingung, tidak percaya diri, tidak dapat memusatkan perhatian, pikiran kosong dan tidak menentu. Oleh karena itu, individu yang memiliki kecemasan berbicara di muka umum tidak dapat berbicara dengan lancar. Kecemasan tersebut harus dikelola agar individu dapat berbicara dengan efektif (Bower dkk., dalam Utami \& Prawitasari, 1991). Salah satu teknik yang dapat digunakan untuk meredakan kecemasan adalah dengan relaksasi (Smith, Hancock, Blake-Mortimer, \& Eckert, 2007). Teknik relaksasi yang digunakan dalam pelatihan ini adalah teknik relaksasi nafas dalam. Kemper (Chiang, Ma, Huang, Tseng \& Hsueh, 2009) menyatakan bahwa dalam praktik klinis, salah satu intervensi psikologis yang populer dilakukan adalah teknik relaksasi nafas dalam yang memanfaatkan koneksi pikiran-tubuh untuk mengontrol simtom kecemasan.

Teknik terakhir yang diberikan kepada para peserta adalah afirmasi positif. Teknik ini diberikan atas dasar bahwa informasi negatif tentang diri akan berpengaruh kepada regulasi diri, meningkatkan afek negatif seperti kecemasan, dan menurunkan harga diri (Reed \& Aspinwall, 1998). Oleh karenanya penting untuk berfokus pada afirmasi diri yang positif agar para peserta dapat menurunkan kecemasan yang dimiliki saat tampil menyampaikan pesan dari Puskesmas. Dengan melakukan afirmasi positif, kader dapat meyakinkan kepda dirinya sendiri tentang kelebihan-kelebihan yang dimilikinya sehingga dapat fokus menyampaikan materi yang harus disampaikannya ke para warga.

\section{KESIMPULAN}

Secara kuantitatif, terdapat penurunan skor kecemasan sebelum dan setelah pelatihan dilaksanakan. Hal tersebut menunjukkan bahwa pelatihan mengatasi kecemasan berbicara di depan warga mampu menurunan kecemasan para kader kesehatan jiwa di Puskesmas Cangkringan. Secara kualitatif, para peserta merasa mendapatkan wawasan dan ilmu yang dapat bermanfaat bagi para peserta. Selain itu, peserta juga mendapatkan manfaat lain yaitu menambah relasi dengan kader dari dusun yang berbeda-beda, sehingga pada saat pelatihan para kader dapat saling berbagi informasi. Peserta merasa dengan berkumpulnya kader dari berbagai dusun yang memiliki permasalahan yang sama (cemas jika berbicara di depan warga), menjadikan muncul rasa senasib dan tidak sendiri. Perasaan senasib tersebut menimbulkan semangat tersendiri dalam diri peserta. Peserta merasa memiliki support group dengan adanya pelatihan yang diselenggarakan. 
Kekurangan dalam pelaksanaan pelatihan ini adalah masalah pengaturan waktu. Waktu yang digunakan untuk berlatih berbicara di dalam kelompok dirasa masih kurang, sehingga peserta berpendapat masih memerlukan pelatihan sejenis. Kekurangan lain adalah tidak adanya kelompok kontrol dalam penelitian ini.

Peserta merasa senang dengan adanya pelatihan mengelola kecemasan berbicara di depan umum. Peserta berharap Puskesmas lebih sering mengadakan pelatihan sejenis di kesempatan-kesempatan mendatang. Terkait dengan harapan peserta dan hasil evaluasi maka hal-hal yang dapat direkomendasikan antara lain:

1. Diadakan pelatihan lanjutan untuk melatih kader berbicara di depan warga. Apabila diadakan pelatihan kembali, sebaiknya diberikan waktu lebih banyak pada saat latihan berbicara di depan umum agar para kader dapat bernar-benar bereksplorasi pada saat berlatih berbicara di depan umum.

2. Kader diberikan pembekalan tentang kesehatan jiwa secara lebih mendalam agar para kader lebih percaya diri karena memiliki bekal pengetahuan yang cukup mengenai kesehatan jiwa.

\section{DAFTAR PUSTAKA}

[1] Berger, B. A., McCroskey, J. C., \& Richmond, V. P. 1984. Communication apprehension and shyness. Dalam W. N. Tinnally, R. S. Beardsley, \& F. R. Cultiss (Eds.). Communication in pharmacy practice: A practical guide for students and practitioners. Philadelphia, PA: Lea \& Febiger (hal. 128-158)

[2] Chiang, L., Ma, W., Huang, J., Tseng, L., \& Hsueh, K. 2009. Effect of relaxationbreathing training on anxiety on asthma signs/symptoms of children with moderate - tosevere asthma: A randomized control trial. International Journal of Nursing Studies, 46:1061-1070.

[3] Dwyer, K. K. 2000. The multidimensional model: Teaching students to self-manage high communication apprehension by self-selecting treatments. Communication Education, 1: $72-81$.

[4] Gallagher, A. G., Ritter, E. M., Champion, H., Higgins, G., Fried, M. P., Moses, G., Smith, C. D., \& Satava, R. M. 2005. Virtual reality simulation for the operating room. Annals of Surgery, 241:364-372.

[5] McCroskey, J. C., \& Richmond, V. P. 1976. The effects of communication apprehension on the perception of peers. Western Speech Communication, 40:14-21.

[6] McCroskey, J. C., Richmond, V . P., Daly, J. A., \& Falcione, R. L. 1977. Studies of the relationship between communication apprehension and self-esteem. Human communication research, 3:269-277.

[7] McCroskey, J. C. 1984. Communication apprehension perspective. Dalam J. A. Daly \& J. C. McCroskey Eds.). Avoiding communication, shyness, reticence, and communication, hal. 13-38. Beverly Hills, CA: Sage Publication.

[8] McCroskey, J. C., \& Beatty, M. J. 1986. Oral communication apprehension. Dalam W. H. Jones, J. M. Cheek, \& S. R. Briggs (Eds.). Shyness: Perspective on research and treatment, hal. 279-293. New York, NY: Plenum Press.

[9] Neenan, M., \& Dryden, W. 2011. Cognitive therapy in a nutshell, second edition. Los Angeles: Sage.

[10] Reed, M. B., \& Aspinwall, L. G. 1998. Self-affirmation reduces biased processing of health risk information. Motovation and Emotion, 22:99-132. 
[11] Smith, C., Hancock, H., Blake-Mortimer, J., \& Eckert, K. 2007. A randomized comparative trial of yoga and relaxation to reduce stress and anxiety. Complementary Therapies in Medicine, 15:77-83.

[12] Utami, M. S., \& Prawitasari, J. E. 1991. Efektivitas relaksasi dan terapi kognitif untuk mengurangi kecemasan berbicara di muka umum. Yogyakarta: Thesis. Program Pascasarjana Fakultas Psikologi Universitas Gadjah Mada. 